\title{
Effect of attitudes of information technologies (IT) preservice teachers and computer programming (CP) \\ students toward programming on their perception regarding their self-sufficiency for programming \\ Bilişim teknolojileri (BT) öğretmen adaylarının ve bilgisayar programcılığı (BP) öğrencilerinin programlamaya karş1 tutumlarinın programlama öz yeterlik algılarına etkisi
}

\author{
Mustafa Yağci ${ }^{1}$
}

\begin{abstract}
Learning programming requires high level of problem solving skills. Therefore, factors effective on students' success in programming have been one of the debated subjects in the literature. Moreover, average success levels of students in programming languages course are usually at low level. The reason lying underneath failure of students could also be their readiness for programming and selfsufficiencies in addition to necessity of high level of thinking skill. In this respect, the purpose of the present research is to investigate attitudes of IT preservice teachers and CP students toward computer programming, their self-sufficiency perception toward programming, and the relationship among them. Data was collected from totally 274 participants including 165 IT preservice teachers and $114 \mathrm{CP}$ students. Research results reveal that IT preservice teachers and $\mathrm{CP}$ students have medium level of attitude and self-sufficiency perception
\end{abstract}

Özet

Programlama öğrenimi üst düzey problem çözme becerileri gerektirmektedir. Bu yüzden öğrencilerin programlama başarılarını etkileyen faktörler literatürde tartışlan bir konu olmuştur. Ayrıca öğrencilerin programlama dilleri derslerinde başarı ortalaması genelde düşük düzeydedir. Öğrencilerin başarısız oluşunun altunda yatan sebep programlama öğreniminin üst düzey düşünme becerisi gerektirmesinin yanında programlamaya yönelik hazırbulunuşlukları da olabilir. Bu bağlamda bu araş̧trmanın amacı BT öğretmen adaylarının ve BP öğrencilerinin bilgisayar programlamaya yönelik tutumları, programlamaya ilişkin öz yeterlik algiları ve bunlar arasındaki ilişkiyi incelemek olarak belirlenmişstir. Veriler 165'i BT öğretmen adayı ve 114'ü BP öğrencisi olmak üzere toplam 274 katilımcidan elde edilmiştir. Araştırma sonuçları BT öğretmen adaylarının ve BP öğrencilerinin orta düzeyde programlamaya yönelik tutuma ve öz yeterlik algisina sahip olduklarını göstermektedir. Cinsiyet, öğrencilerin

\footnotetext{
1 Asst. Prof., Ahi Evran University, Education Faculty, Department of Computer Education and Instructional Technology, mustafayagci06@gmail.com
} 
Yağc1, M. (2016). Bilişim teknolojileri (BT) öğretmen adaylarının ve bilgisayar programcıllğı (BP) öğrencilerinin programlamaya karşı tutumlarının programlama öz yeterlik algilarına etkisi. International Journal of Human Sciences, 13(1), 1418-1432. doi:10.14687/ijhs.v13i1.3502

programming. Another research reports that IT preservice teachers have higher self-sufficiency perception regarding programming with respect to CP students. Additionally, no significant relationship was found between attitudes of students toward computer programming and their self-sufficiency perceptions regarding programming.

Keywords: Programming, Attitude Toward Programming, Programming Self-Efficacy, CEIT, Department of Computer Programming.

(Extended English abstract is at the end of this document) tutum ve algilarında anlamlı bir farklılık oluşturmamıştır. Sınıf düzeyi BT öğretmen adaylarının tutum ve öz yeterlik algilarında farklılık oluşturmazken BP öğrencilerinin tutum ve algilarında anlamlı bir farklılık oluşturmuştur. Bir diğer araştırma sonucu ise BT öğretmen adaylarının BP öğrencilerinden daha yüksek düzeyde programlamaya ilişkin öz yeterlik algisına sahip olduğudur. Ayrıca öğrencilerin bilgisayar programlamaya yönelik tutumları ile programlamaya ilişkin öz yeterlik algıları arasında anlamlı bir ilişki bulunmamıştır.

Anahtar Kelimeler: Programlamaya Karşı Tutum, Programlama Öz-Yeterlik Alg1s1, Programlama, BÖTE, Bilgisayar Programcillğı.

\section{Giriş}

Programlama öğrenimi öğrenciler için üst düzey bilişsel düşünme becerilerine sahip olmay1 gerektirir (Lau ve Yuen, 2009:4). Öğrencilerin programlama dersinde başarılı olmaları ve hedef kazanımlara ulaşabilmeleri, problem çözme becerilerine ve programlamaya yönelik tutum ve öz yeterlik algılarına bağlıdır. Bu konuda Ülkemizde yapılan bilimsel araştırmaların tamamına yakını öğrencilerin program geliştirmeye karşı düşük yada orta düzeyde bir tutum içinde olduğunu göstermektedir (Askar ve Davenport, 2009:2; Başer, 2013:3). Ayrıca literatürden öğrencilerin programlama eğitimini zor buldukları da anlaşılmaktadır.

Öğrencilerin programlamaya yönelik tutumlarının düşük düzeyde olması programlama başarılarını olumsuz yönde etkilemektedir (Altun ve Mazman, 2012:1). Öğrencilerin programlama başarısını etkileyen faktörler arasında tutum, motivasyon ve demografik özellik gibi faktörler yer almaktadır (Başer, 2013; Korkmaz ve Demir 2012). Nitekim Haşlaman ve Aşkar (2007) programlama dilleri dersini alan öğrencilerin başarıları üzerinde öz yeterlik algılarının pozitif ve güçlü etkisi olduğunu (s. 1) belirtmiştir. Ayrıca üniversitelerde okutulan "Programlamaya Giriş" derslerinde öğrencilerin programlama öz yeterlik algıları üzerine yapılan çalışmaların sonuçları (Mazman ve Altun, 2013) öğrencilerin programlamaya karşı tutumlarının değiştiği yönündedir.

Programlama dillerinin öğretimi konusunda yapılan deneysel çalışmalar iyi yapılandırılmış problem çözme becerileri kazandıran öğretimsel ortamların öğrencilerin başarılarını ve programlama algılarını olumlu yönde etkilediğini göstermektedir (Uysal, 2014). Programlama dilleri dersinin güçlügünden yola çıkarak daha itinalı tasarlanan ders içerikleri öğrencilerin hedef kazanımlara ulaşma çabasını ve isteğini artırmaktadır (Forte ve Guzdial, 2005:5).

Bilgisayar ile ilgili eğitim veren öğretim kurumlarının neredeyse tümünde programlama dilleri dersi verilmektedir. Eğitim fakültelerinin BÖTE bölümlerinde programlamaya ilişkin okutulan dersler ve ders saatleri aşağıdaki gibidir.

1. 2. sinifta Programlama Dilleri I ve Programlama Dilleri II (3 Teorik, 2 Uygulama)

2. 3. sinıfta İnternet Tabanlı Programlama (3 Teorik, 2 Uygulama)

3. Web Tasarım1 (2 Teorik, 2 Uygulama)

Toplam: 14 saattir.

Meslek Yüksekokullarının bilgisayar programcıllğı bölümlerinde programlamaya ilişkin okutulan dersler ve ders saatleri ise;

1. Programlama Temelleri (3 Teorik, 1 Uygulama)

2. Web Tasarımının Temelleri (2 Teorik, 1 Uygulama) 
Yağc1, M. (2016). Bilişim teknolojileri (BT) öğretmen adaylarının ve bilgisayar programcıllğı (BP) öğrencilerinin programlamaya karşı tutumlarının programlama öz yeterlik algilarına etkisi. International Journal of Human Sciences, 13(1), 1418-1432. doi:10.14687/ijhs.v13i1.3502

3. Internet Programciliğ1 I (3 Teorik, 1 Uygulama)

4. Görsel Programlama I (3 Teorik, 1 Uygulama)

5. Nesne Tabanlı Programlama I (3 Teorik, 1 Uygulama)

6. İnternet Programcillğ II (3 Teorik, 1 Uygulama)

7. Görsel Programlama II (3 Teorik, 1 Uygulama)

8. Nesne Tabanlı Programlama II (3 Teorik, 1 Uygulama) Toplam: 31 saattir.

BT öğretmen adaylarına okutulan programlamaya yönelik ders saatinin BP öğrencilerine okutulan ders saatinden daha az olduğu görülmektedir. BT öğretmen adaylan 4 yıllık fakülte eğitiminde sadece 14 saat programlama dersi almaktadır. Bu da BT öğretmen adaylarının programlamada başarısızlığını tetikleyen unsurlardan birisi olabilir.

Literatürde öğrencilerin programlamaya yönelik tutumlarını ve çeşitli demografik özellikleri arasındaki ilişkiyi inceleyen çok sayıda araştırmaya rastlanmıştır. Ancak öğrencilerin programlamayı nasıl öğrendikleri, programlamaya karşı tutumları ve algıları ile programlama başarıları arasındaki ilişki az bilinen bir konudur. Öğrencilerin programlamaya yönelik tutumlarının ve algılarının belirlenmesi, öğrenci farklılıklarının anlaşılmasına ve öğretmen merkezli öğretimden öğrenci merkezli öğretime geçişin sağlanmasına katkıda bulunabilir. Ayrıca literatürde öğrencilerin programlama performansını etkileyen faktörlerin incelenmesi önerilmektedir (Cetin ve Ozden, 2015:4; Korkmaz ve Altun, 2013:14; Başer, 2013:11). Gelişmiş teknolojik araçlar neredeyse tüm öğretim alanlarında sıkça kullanılmaktadır. Bu yüzden Lau ve Yuen'in de (2009) belirttiği gibi eğitim teknolojisinde bilgi okur yazarllğının gelişmesinde programlama öğrenim becerileri önemli bir rol oynamaktadır (s. 2). Bu yüzden eğitim faaliyetlerinde bulunan bireylerin programlama becerilerinin belirlenmesi ve geliştirilmesine yönelik çalışmaların yapılması ayrıca önemlidir. Bu doğrultuda bu çalışmanın amacı BT öğretmen adaylarının ve BP öğrencilerinin bilgisayar programlamaya yönelik tutumlarını ve programlamaya ilişkin öz yeterlik algılarını belirlemek ve aralarındaki ilişkiyi incelemek olarak belirlenmiştir. Bu genel amaç doğrultusunda aşağıdaki araştırma sorularına cevap aranmıştur;

a) BT öğretmen adaylarının ve BP öğrencilerinin bilgisayar programlamaya yönelik tutumları nedir?

b) BT öğretmen adaylarının ve BP öğrencilerinin bilgisayar programlamaya yönelik tutumları demografik özelliklerine (cinsiyet, sınıf, mezun olunan lise türü, öğrenim düzeyi) göre anlamlı bir farklılık göstermekte midir?

c) BT öğretmen adaylarının ve BP öğrencilerinin programlamaya ilişkin öz yeterlik algıları nedir?

d) BT öğretmen adaylarının ve BP öğrencilerinin programlamaya ilişkin öz yeterlik alg1ları demografik özelliklerine (cinsiyet, sınıf, mezun olunan lise türü, öğrenim düzeyi) göre anlamlı bir farklılık göstermekte midir?

e) BT öğretmen adaylarının ve BP öğrencilerinin bilgisayar programlamaya yönelik tutumları ile programlamaya ilişkin öz yeterlik algıları arasında anlamlı bir ilişki var mıdır?

\section{Yöntem}

\section{Çalısma Grubu}

Araştırmanın çalışma grubunu, 2014-2015 eğitim-öğretim yılı bahar döneminde öğrenim gören Ahi Evran Üniversitesi Eğitim Fakültesi BÖTE Bölümü öğretmen adayları ve Teknik Bilimler Meslek Yüksekokulu BP bölümü öğrencileri oluşturmaktadır.

279 katılımcıya web ortamında geliştirilen bir form ve anket dağıtımı yolu ile ulaşılmıştır. Çalışma grubunun cinsiyet, sınıf ve mezun olunan lise türüne göre dağılımları Tablo 1' de özetlenmiştir. 
Yağc1, M. (2016). Bilișim teknolojileri (BT) öğretmen adaylarının ve biloisayar programcıllı̆ı (BP) öğrencilerinin programlamaya karşı tutumlarının programlama öz yeterlik algılarına etkisi. International Journal of Human Sciences, 13(1), 1418-1432. doi:10.14687/ijhs.v13i1.3502

Tablo 1. BÖTE Bölümü Öğretmen Adaylarının Demografik Özellikleri

\begin{tabular}{|c|c|c|c|c|c|}
\hline \multirow{2}{*}{ Değişken } & \multirow{2}{*}{ Özellik } & \multicolumn{2}{|c|}{ Lisans } & \multicolumn{2}{|c|}{ Ön Lisans } \\
\hline & & f & $\%$ & f & $\%$ \\
\hline \multirow{2}{*}{ Cinsiyet } & Erkek & 81 & 49,1 & 88 & 77,2 \\
\hline & Kadin & 84 & 50,9 & 26 & 22,8 \\
\hline \multirow{4}{*}{ Sinif } & 1 & 41 & 24,8 & 38 & 33,3 \\
\hline & 2 & 39 & 23,6 & 72 & 63,2 \\
\hline & 3 & 51 & 30,9 & 2 & 1,8 \\
\hline & 4 & 34 & 20,6 & 2 & 1,8 \\
\hline \multirow{3}{*}{ Mezun Olunan Lise Türü } & Meslek Lisesi & 101 & 61,2 & 85 & 74,6 \\
\hline & Normal Lise & 37 & 22,4 & 26 & 22,8 \\
\hline & Anadolu Meslek Lisesi & 27 & 16,4 & 3 & 2,6 \\
\hline Toplam & & 165 & 100 & 114 & 100,0 \\
\hline
\end{tabular}

\section{Veri Toplama Araçları}

Çalışmada veri toplama aracı olarak "programlamaya ilişkin öz yeterlik ölçeğì" ve "bilgisayar programlamaya karşı tutum ölçeği” kullanılmıştır.

Programlamaya İlişkin Öz Yeterlik Algısı Ölçeği: Üniversite öğrencilerinin programlamaya ilişkin öz yeterlik algılarını belirlemek için Altun ve Mazman,'ın (2012), ilk olarak Ramalingam ve Wiedenbeck'in (1998) geliştirdiği ölçeği Türkçeye uyarlayarak geliştirdiği 9 maddeden ve iki faktörden oluşan 7'li likert tipi "Programlamaya İlişkin Öz Yeterlik" ölçeği kullanılmıştır. Orjinali 32 madde olan ölçek faktör analizi ve güvenirlik analizi sonucu 9 maddeden oluşmuştur. Ölçek, basit programlama görevleri (Madde 1..3) ve karmaşık programlama görevleri (Madde 4..9) faktörlerinden oluşmaktadır. Ölçekteki maddeler "1Kendime hiç güvenmiyorum”, "2-Genellikle güvenmiyorum”, “3-Biraz güveniyorum”, "4-Yüzde elli yüzde elli", "5-Oldukça güveniyorum", "6-Genellikle güveniyorum" ve "7-Tamamen güveniyorum” şeklinde derecelendirilmiştir. Tüm ölçek için iç tutarlık katsayısı (Cronbach Alpha) ise .928 olarak hesaplanmiştır.

Bilgisayar Programlamaya Karşı Tutum Ölçeği: Öğrencilerin bilgisayar programlamaya yönelik tutumlarını ölçmek için Başer'in (2013) orjinalini Wiebe, Williams, Yang, ve Miller'in (2003) geliştirdiği ölçeği temel alarak geliştirdiği 38 madde ve dört faktörden oluşan beş’li likert tipi "Bilgisayar Programlamaya Karşı Tutum Ölçeği’" kullanılmıştır. 47 maddeden oluşan orjinal ölçekten faktör analizi ve güvenirlik analizi sonucu 9 madde çıkarılmıştır. Ölçeğin geliştirilmesinde veriler 179'u BÖTE bölümüne ve 41'i Bilgisayar Mühendisliği bölümüne kayıtlı toplam 220 öğrenciden elde edilmiştir. Ölçek, programlamada kendine güven ve güdüleme (Madde 1..11, 33, $34,35,36,37,38$ ), programlamanın faydası (Madde 23..32), programlamada başarıya karşı tutum (Madde 12..19) ve programlamada başarının sosyal algısı (20..22) alt boyutlarından oluşmaktadır. Ölçeğin alt boyutlarına ilişkin iç tutarlık katsayıları .618 ve .944 arasında değerler almaktadır. Tüm ölçek için iç tutarlık katsayısı (Cronbach Alpha) ise .947 olarak hesaplanmıştır. Ölçekteki maddeler "1-Tamamen Katıliyorum", "2-Katiliyorum", "3-Kararsızım", "4-Katılmiyorum" ve "5Tamamen Katılmıyorum" şeklinde derecelendirilmiştir. Ölçekten toplamda alınabilecek en düşük puan 38 en yüksek puan ise 190'dır. Ölçekten alınan puan 190'a yaklaştıkça bilgisayar programlamaya karşı olumlu tutum artmakta, 38'e yaklaştıkça ise azalmaktadır.

\section{Verilerin Toplanması ve Analizi}

Verilerin analizine başlamadan önce uygulanacak istatistiksel yöntemi belirlemek için Kolmogorov-Smirnov normalite testine bakılmıstır. Bilgisayar programlamaya yönelik tutum ölçeğine dair çarpıklık katsayısının (.759) çarpıklık standart hatasına (.189) bölünmesi ile bulunan çarpıklık değeri 4.015 olarak hesaplanmıştır. Bu değer .05 anlamlık düzeyine göre -1.96 ile 1.96 aralığının dışında yer aldığı için verilerin normal dağılım göstermediği anlaşılmıştır. Çünkü, çarpıklık değeri (\%5 anlamlılık düzeyine göre), 1.96'nın üzerinde veya -1.96'nın altındaki değerler .05 anlamlılık düzeyinde kabul edilmektedir (Kalayc1, 2009, s. 6). Programalamaya ilişkin öz 
Yağc1, M. (2016). Bilişim teknolojileri (BT) öğretmen adaylarının ve bilgisayar programcıllğı (BP) öğrencilerinin programlamaya karşı tutumlarının programlama öz yeterlik algilarına etkisi. International Journal of Human Sciences, 13(1), 1418-1432. doi:10.14687/ijhs.v13i1.3502

yeterlik algısını belirleyen veriler de aynı şekilde normal dağılım göstermemiştir. KolmogorovSmirnov normallik testi analiz sonuçları, bağımlı değişkenler için tüm gruplarda normal dağılım göstermediğinden dolayı non-parametrik testler kullanılmıştır. Bu kapsamda elde edilen verilerin analizi sürecinde; betimsel istatistikler olarak frekans (f), yüzde (\%), ortalama $(\mathrm{X})$ ve standart sapma (Ss) değerleri, açımlayıcı istatistik tekniklerinde ise Kruskal Wallis ve Mann-Whitney U testleri kullanılmıştır. "Bilgisayar programlamaya karşı tutum ölçeğị" için veri analizi sonrasında elde edilen bulguların yorumlanmasında kullanılan değerlendirme ölçeğinde; (5-1) / 3 değerlendirme aralığ1 temel alınmış olup ortalama puan sınırları ile bilgi seviyeleri arasındaki ilişki düzeyi; 1 - 2.33 "Düşük Düzey", 2.34 - 3.67 "Orta Düzey", 3.68 - 5.00 "İleri Düzey" şeklindedir.

Katılımcıların bilgisayar programlamaya yönelik tutumları ile programlamaya ilişkin öz yeterlik algıları arasındaki ilişkiyi belirlemek için ise Sperman sıra korelasyonu testleri kullanılmıştır. Fark ve ilişkilerin anlamlılık derecesine $\mathrm{p}<.05$ düzeyinde bakilmıştır.

\section{Bulgular ve Yorumlar}

Araştırma sonuçları aşağıda özetlenmiştir.

a. Öğgrencilerin bilgisayar programlamaya yönelik tutumları nedir?

Öğrencilerin bilgisayar programlamaya yönelik tutumlarına ilişkin betimsel istatistik sonuçları Tablo 2'de verilmiștir.

Tablo 2. Öğrencilerin Bilgisayar Programlamaya Yönelik Tutumlarına İlişkin Betimsel İstatistik Sonuçları

\begin{tabular}{|c|c|c|c|c|c|c|}
\hline \multirow[t]{2}{*}{ Programlamaya Yönelik Tutum } & \multicolumn{3}{|c|}{ Lisans } & \multicolumn{3}{|c|}{ Ön Lisans } \\
\hline & $\mathbf{N}$ & $\mathbf{X}$ & Ss & $\mathbf{N}$ & $\mathbf{X}$ & Ss \\
\hline Programlamada kendine güven ve güdüleme & & 2,9660 & 41685 & & 2,8550 &, 49230 \\
\hline Programlamanın faydası & & 2,9370 & ,42358 & & 2,9323 &, 54798 \\
\hline Programlamada başarıya karșı tutum & 165 & 2,5220 & 65854 & 114 & 2,4267 & ,74463 \\
\hline Programlamada bașarının sosyal algisı & & 3,8586 &, 86262 & & 3,5656 & 1,18913 \\
\hline Genel & & 2,9353 & ,37149 & & 2,8402 & 45154 \\
\hline
\end{tabular}

Tablo 2'den BT öğretmen adaylarının bilgisayar programlamaya yönelik tutum ortalama puanlarının tüm alt boyutlar için 2.52 ile 3.86 arasında değiştiği görülmektedir. Kattlımciların tutumları "Programlamada başarının sosyla algısı" alt boyutu için ileri düzey, "programlamada kendine güven ve güdüleme", "programlamanın faydası" ve "programlamada başarıya karşı tutum" alt boyutlarında ise orta düzeydedir. BT öğretmen adaylarının programlamaya yönelik genel tutumlarının ise orta düzeyde olduğu görülmektedir. BP öğrencilerinin ortalama puanları 2.42 ile 3.56 aralığında değişmektedir. BP öğrencileri de BT öğretmen adayları gibi en yüksek ortalama puanı "programlamada başarının sosyla algısı" alt boyutundan en düşük ortalama puanı ise yine BT öğretmen adaylarında olduğu gibi "programlamada başarıya karşı tutum" alt boyutundan almışlardır. $\mathrm{Bu}$ bulgu BP öğrencilerinin orta düzeyde programlamaya ilişkin tutuma sahip olduklarını göstermektedir. Bu sonuç literatür ile büyük oranda benzerlik göstermektedir. Korkmaz ve Altun, (2013) ile Başer, (2013) bilgisayar mühendisliği ve böte bölümü öğrencilerinin genel olarak programlama öğrenmeye orta düzeyde eğilimli olduklarını öte yandan programlamaya dönük tutumlarının özellikle mühendislik bölümü öğrencilerinin lehinde daha yüksek olduğunu belirtmiştir. Özyurt ve Özyurt,'a (2015) göre de bilgisayar programcıllğı öğrencilerinin programlamaya yönelik tutumları olumludur.

b. Öğrencilerin bilgisayar programlamaya yönelik tutumları demografik özelliklerine (cinsiyet, sınıf, mezun olunan lise türü, öğrenim düzeyi) göre anlamlı bir farklılık göstermekte midir?

i. BT öğretmen adaylarının ve BP öğrencilerinin bilgisayar programlamaya yönelik tutumları cinsiyete göre anlamlı bir farklılık göstermekte midir? 
Yağc1, M. (2016). Bilişim teknolojileri (BT) öğretmen adaylarının ve bilgisayar programcıllğı (BP) öğrencilerinin programlamaya karşı tutumlarının programlama öz yeterlik algılarına etkisi. International Journal of Human Sciences, 13(1), 1418-1432. doi:10.14687/ijhs.v13i1.3502

Öğrencilerin bilgisayar programlamaya yönelik tutumlarında cinsiyetlerine göre istatistiksel olarak anlamlı bir farklılık gösterip göstermediğini belirlemek amacıyla gerçekleştirilen MannWhitney U testi sonuçlarına Tablo 3'de yer verilmiştir.

Tablo 3. Öğrencilerin Cinsiyetlerine Göre Bilgisayar Programlamaya Yönelik Tutumlarına İlişkin Mann Whitney U Testi Sonuçları

\begin{tabular}{lllllll}
\hline \multirow{2}{*}{ Cinsiyet } & \multirow{2}{*}{$\mathbf{N}$} & \multicolumn{5}{c}{ Ortalama Dă̈ılım } \\
\cline { 3 - 7 } & & Faktör 1 & Faktör 2 & Faktör 3 & Faktör 4 & Genel \\
\hline Erkek & 169 & 135,35 & 140,70 & 136,71 & 145,30 & 136,04 \\
Kadın & 110 & 147,15 & 138,92 & 145,05 & 131,85 & 146,08 \\
\hline Mann Whitney U & & 8508,500 & 9176,500 & 8739,500 & 8398,500 & 8626,000 \\
Z & $-1,199$ &,- 181 &,- 849 & $-1,385$ & $-1,018$ \\
p & &, 230 &, 856 &, 396 &, 166 &, 309 \\
\hline
\end{tabular}

${ }^{*} \mathrm{p}<=.05$

Tablo 3'den BT öğretmen adaylarının ve BP öğrencilerinin bilgisayar programlamaya yönelik tutumlarının ölçeğin tüm alt boyutları için cinsiyet değişkenine göre istatistiksel olarak anlamlı bir farklılık göstermediği anlaşılmaktadır. Bu bulgu öğretmen adaylarının bilgisayar programlamaya yönelik tutumlarının cinsiyete göre değişmediğini göstermektedir. Bu sonuç Bakr, (2011) ve Lau ve Yuen,'un (2009) bulguları ile örtüşmektedir. Deneysel bir çalışma ile öğrencilerin programlama başarısını ve programlamaya yönelik tutumlarını inceleyen Robinson, (1995) yöntemsel farklılıkların cinsiyet üzerinde etkisi olmadığı sonucuna ulaşmıştır (s. 1). İçerik analizi yöntemi ile cinsiyetin bilgisayar programlamaya yönelik tutuma etkisini inceleyen (Whitley, 1997:15) öğrencilerin bilgisayar ile ilgili yaklaşımlarına cinsiyetin etken olmadığı sonucuna ulaşmıştır. Bunun aksine, literatürde programlamaya yönelik tutum ve problem çözme becerilerinde cinsiyetin önemli bir etken olduğu sonucuna da ulaşıldığ1 gözlenmiştir. Brosnan, (1998), Askar ve Davenport, (2009) ile Başer, (2013) bilgisayara yönelik tutum açısından erkeklerin kadınlardan daha yüksek tutuma sahip olduğu sonucunu bulmuşlardır. $\mathrm{Bu}$, cinsiyetin programlama görevlerinin çözümünde önemli bir değişken (Milic, 2009:4) olmasından kaynaklanabilir.

ii. Öğrencilerin bilgisayar programlamaya yönelik tutumları sınıfa göre anlamlı bir farklılık göstermekte midir?

Bağımsız gruplar için yapılan “Kruskal Wallis” sonuçları Tablo 4'de verilmiştir.

Tablo 4. Öğrencilerin Sınıf Düzeylerine Göre Bilgisayar Programlamaya Yönelik Tutumlarına İlişkin Kruskal Wallis Testi Sonuçları

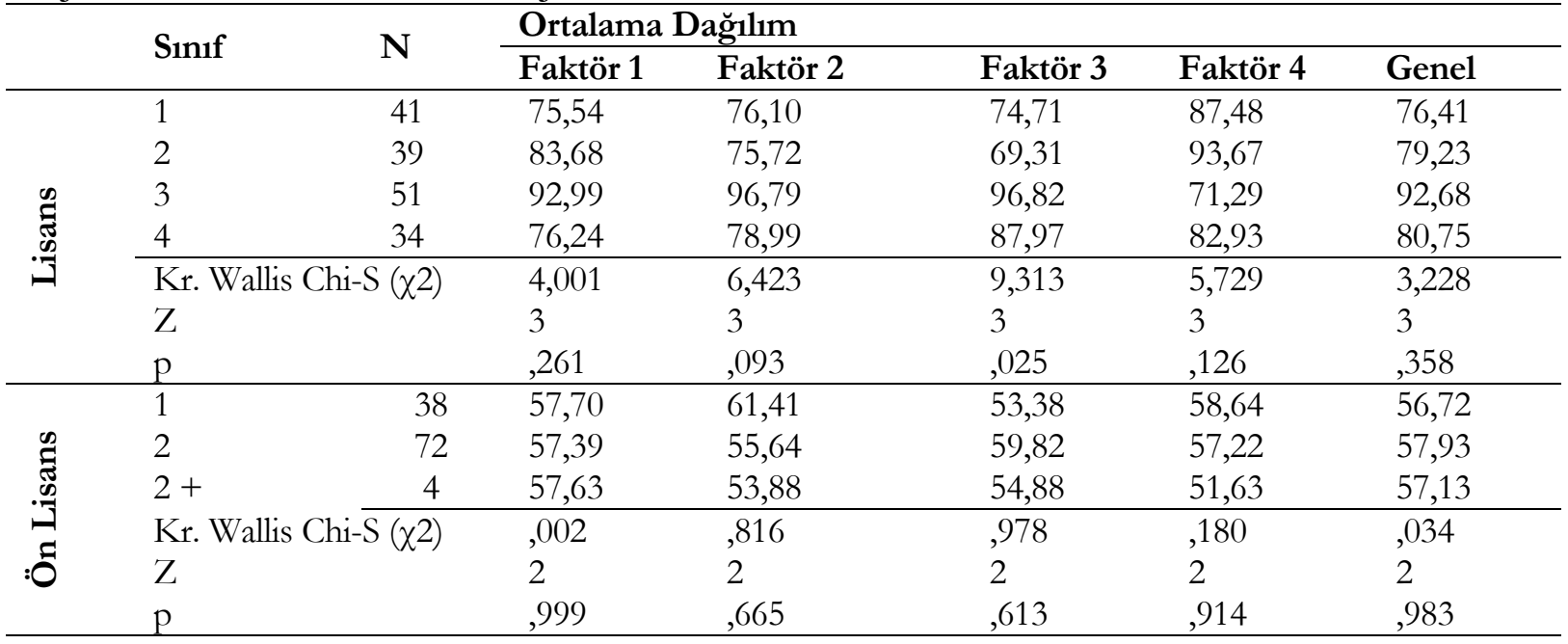

${ }^{*} \mathrm{p}<=.05$ 
Yağc1, M. (2016). Bilişim teknolojileri (BT) öğretmen adaylarının ve bilgisayar programcıllğı (BP) öğrencilerinin programlamaya karşı tutumlarının programlama öz yeterlik algilarına etkisi. International Journal of Human Sciences, 13(1), 1418-1432. doi:10.14687/ijhs.v13i1.3502

Tablo 4'de BT öğretmen adaylarının bilgisayar programlamaya yönelik tutumları ile sinıf düzeyleri arasında; "programlamada başarıya karşı tutum" (U=9.313, p=.025, Faktör 3) alt boyutunda 3. sınıfa devam eden öğretmen adaylarının lehine istatistiksel olarak anlamlı bir farklılık görülmektedir. 1, 2 ve 4. faktörlerde ise sinıflara göre anlamlı bir farklılık olmadığ1 gözlenmiştir. Diğer bir ifade ile öğretmen adaylarının bilgisayar programlamaya yönelik tutumları sınıf düzeyine göre yalnızca "programlamada başarıya karşı tutum" alt boyutuna göre değişmektedir. BP öğrencilerinde ise tutum ile sınıf düzeyi arasında anlamlı bir farklılık bulunmamıştır. Yani BP öğrencilerinin tutumları yüksekokul öğrenimleri boyunca anlamlı bir değişiklik göstermemiştir. Literatürde de bu araştırmada olduğu gibi farklı sonuçlara ulaşılmıştır. Mazman ve Altun, (2013), öğrencilerin programlamaya ilişkin öz yeterlik algılarının programlama dersini aldıktan sonra anlamlı derecede arttı̆̆ını ifade etmiştir (s. 4). Benzer şekilde Özyurt ve Özyurt, (2015) öğrencilerin sınıf düzeyi ile programlamaya yönelik tutumları arasıda anlamlı ilişki bulmuştur (s. 13). Öte yandan programlamaya yönelik tutumdaki farkllilk ilk programlama deneyiminden sonra azalmaktadır. Bunun aksine Yıldırım ve Kaban, (2010) sınıf düzeyi ile öğrencilerin bilgisayar destekli eğitime yönelik tutumları arasında anlamlı bir ilişki bulunmadığ1 (s. 1) sonucuna ulaşmıştır. Yine benzer şekilde Bakr, (2011) öğretmenlerin deneyimlerinin bilgisayara yönelik tutumlarını etkilemediğini (s. 8) bulmuştur.

iii. Öğrencilerin bilgisayar programlamaya yönelik tutumları mezun oldukları lise türüne göre anlamlı bir farkllilı göstermekte midir?

Öğrencilerin bilgisayar programlamaya yönelik tutumlarının mezun oldukları lise türüne göre istatistiksel olarak anlamlı bir farkllılı gösterip göstermediğini ölçmek amacıyla bağımsız gruplar için yapılan Kurskal Wallis testi sonuçları Tablo 5'de verilmiştir.

Tablo 5. Öğrencilerin Mezun Oldukları Lise Türüne Göre Bilgisayar Programlamaya Yönelik Tutumlarına İlişkin Kruskal Wallis Testi Sonuçları

\begin{tabular}{lcrrrrr}
\hline \multirow{2}{*}{ Mezun Olunan Lise Türü } & \multirow{2}{*}{ N } & \multicolumn{5}{c}{ Ortalama Dağ1lim } \\
\cline { 3 - 6 } & & Faktör 1 & Faktör 2 & Faktör 3 & Faktör 4 & Genel \\
\hline Meslek Lisesi & 186 & 137,27 & 143,01 & 134,22 & 138,23 & 136,80 \\
Normal Lise & 63 & 145,33 & 129,23 & 138,59 & 142,83 & 142,04 \\
Anadolu Meslek L. & 30 & 145,75 & 143,97 & 178,78 & 145,05 & 155,58 \\
\hline Kr. Wallis Chi-S $(\chi 2)$ & &, 645 & 1,473 & 8,018 &, 295 & 1,458 \\
Z & 2 & 2 & 2 & 2 & 2 \\
p &, 724 &, 479 &, 018 &, 863 &, 482 \\
\hline
\end{tabular}

${ }^{*} \mathrm{p}<=.05$

Tablo 5'de öğrencilerin mezun oldukları lise türüne göre bilgisayar programlamaya yönelik tutumları incelendiğinde; en yüksek ortalamanın 155.58 puan ortalaması ile Anadolu Meslek Lisesi mezunlarına ait olduğu en düşük ortalama puanın ise 136.80 puan ortalaması ile Meslek Lisesi mezunlarına ait olduğu görülmektedir. Kruskal Wallis testi sonuçlarına göre; öğrencilerin "programlamada başar1ya karşı tutum" (U=8.018, $\mathrm{p}=.018)$ alt boyutunda mezun olunan lise türüne göre Anadolu Meslek Lisesi mezunlarının lehinde anlamlı bir farklılık gösterdiği anlaşılmaktadır. Diğer bir ifade ile Anadolu Meslek Lisesi mezunlarının programlamada başarıya karşı tutumları diğer lise mezunlarına göre daha yüksektir. Diğer alt boyutlarda ise mezun olunan lise türünün tutum üzerinde anlamlı bir farklılık oluşturmadığı görülmektedir.

iv. Öğrencilerin bilgisayar programlamaya yönelik tutumlanı öğrenim düzeylerine (lisans ön lisans) göre anlamlı bir farklılık göstermekte midir?

Öğrencilerin öğrenim düzeylerine göre programlamaya yönelik tutumlarında bir farklılık olup olmadığını ölçmek için yapılan Mann Whitney U testi sonuçları Tablo 6'da verilmiştir. 
Yağc1, M. (2016). Bilişim teknolojileri (BT) öğretmen adaylarının ve bilgisayar programcıllğı (BP) öğrencilerinin programlamaya karşı tutumlarının programlama öz yeterlik algilarına etkisi. International Journal of Human Sciences, 13(1), 1418-1432. doi:10.14687/ijhs.v13i1.3502

Tablo 6. Öğrencilerin Öğrenim Düzeylerine Göre Bilgisayar Programlamaya Yönelik Tutumlarına İlişkin Mann Whitney U Testi Sonuçları

\begin{tabular}{lrrrrrr}
\hline \multirow{2}{*}{ Cinsiyet } & \multirow{2}{*}{$\mathbf{N}$} & \multicolumn{5}{c}{ Ortalama Dağ1lım } \\
\cline { 3 - 7 } & & Faktör 1 & Faktör 2 & Faktör 3 & Faktör 4 & \multicolumn{1}{c}{ Genel } \\
\hline Ön Lisans & 114 & 124,86 & 140,86 & 132,43 & 130,75 & 128,70 \\
Lisans & 165 & 150,46 & 139,41 & 145,23 & 146,39 & 147,81 \\
\hline Mann Whitney U & 7678,500 & 9307,000 & 8541,500 & 8350,000 & 8117,000 \\
Z & $-2,617$ &,- 149 & $-1,313$ & $-1,621$ & $-1,948$ \\
p &, 009 &, 882 &, 189 &, 105 &, 051 \\
\hline
\end{tabular}

${ }^{*} \mathrm{p}<=.05$

Tablo 6'dan BT öğretmen adaylarının ve BP öğrencilerinin bilgisayar programlamaya yönelik tutumlarının "programlamada kendine güven ve güdüleme" (U=7678.50, $\mathrm{p}=.009)$ alt boyutunda öğrenim düzeyine göre istatistiksel olarak anlamlı bir farklılık gösterdiği diğer alt boyutlarda ise anlamlı bir farklılık göstermediği anlaşılmaktadır. Diğer bir ifade ile hem BT öğrencilerinin hem de BP öğrencilerinin programlamaya yönelik tutumları "programlamada kendine güven ve güdüleme" alt boyutu dışında önemli bir farklilık göstermemektedir. Literatürde bilgisayar programcıllğı dersi alan öğrencilerin bölüm bazında karşılaştırıldı̆̆1 görülmektedir. Bu yüzden bu araştırma maddesi için literatürden kıyaslamalar yapılamamıştır.

c. BT öğretmen adaylarının ve BP öğrencilerinin programlamaya ilişkin öz yeterlik alg1lar1 nedir?

Öğrencilerin bilgisayar programlamaya ilişkin öz yeterlik algıları ve alt boyutlarına göre puan ortalamalarına ilişkin betimsel istatistik sonuçları Tablo 7'de görülmektedir.

Tablo 7. Öğgrencilerin Programlamaya Yönelik Öz Yeterlik Algılarına İlişkin Betimsel İstatistik Sonuçları

\begin{tabular}{lccccccccc}
\hline $\begin{array}{l}\text { Programlamaya Yönelik } \\
\text { Tutum }\end{array}$ & \multicolumn{2}{c}{ Lisans } & \multicolumn{3}{c}{ Ön Lisans } & \multicolumn{3}{c}{ Genel } \\
\hline & $\mathbf{N}$ & $\mathbf{X}$ & \multicolumn{1}{c}{ Ss } & $\mathbf{N}$ & $\mathbf{X}$ & \multicolumn{1}{c}{ ss } & N & X & Ss \\
\hline Basit Programlama Görevleri & & 17,63 & 3,613 & & 14,16 & 5,407 & & 16,21 & 4,744 \\
Karmaşık Programlama & 165 & 26,83 & 8,250 & 114 & 19,03 & 9,336 & 279 & 23,64 & 9,505 \\
Görevleri & & 44,46 & 10,661 & & 33,18 & 13,383 & & 39,85 & 13,065 \\
Genel & & & & & & & &
\end{tabular}

Tablo 7'de BT öğretmen adaylarının programlamaya ilişkin öz yeterlik ortalama puanlarının 44.46, BP programcllı̆ öğrencilerinin ise 33.18 olduğu görülmektedir. Bu sonuca göre BT öğretmen adaylarının programlamaya ilişkin öz yeterlik algılarının BP öğrencilerinden daha yüksek olduğunu söyleyebiliriz. Ayrıca öğrencilerin ölçeğin "karmaşık programlama görevleri” ( $\bar{X}=$ 23.64) alt boyutundan aldıkları puanın "basit programlama görevleri” ( $\bar{X}=16.21)$ alt boyutundan aldıkları puana göre oldukça yüksek olduğu görülmektedir. Sonuç olarak öğrencilerin programlamaya ilişkin öz yeterlik alg1ları orta düzeyde olmakla birlikte lisans öğrencilerinin puan ortalamaları daha yüksektir. Literatür bu araştırma sonuçlarını destekler niteliktedir (Özyurt ve Özyurt,'a (2015). Mazman ve Altun, (2013) yaptığ1 deneysel bir çalışma sonucunda programlama deneyiminden sonra öğrencilerin öz yeterlik algilarının programlama dersi almadan önceki durumuna göre anlamlı farklılık gösterdiği sonucunu bulmuştur. 
Yağc1, M. (2016). Bilişim teknolojileri (BT) öğretmen adaylarının ve bilgisayar programcıllğı (BP) öğrencilerinin programlamaya karşı tutumlarının programlama öz yeterlik algılarına etkisi. International Journal of Human Sciences, 13(1), 1418-1432. doi:10.14687/ijhs.v13i1.3502

d. BT öğretmen adaylarının ve BP öğrencilerinin programlamaya ilişkin öz yeterlik algıları demografik özelliklerine (cinsiyet, sınıf, mezun olunan lise türü, öğrenim düzeyi) göre anlamlı bir farklılık göstermekte midir?

i. $\quad$ Ögrencilerin programlamaya ilişkin öz yeterlik algıları cinsiyete göre anlamlı bir farklılık göstermekte midir?

Tablo 8. Öğrencilerin Cinsiyetlerine Göre Programlamaya Yönelik Öz Yeterlik Algılarına İlişkin Mann Whitney U Testi Sonuçları

\begin{tabular}{lcccc}
\hline \multirow{2}{*}{ Cinsiyet } & \multirow{2}{*}{$\mathbf{N}$} & \multicolumn{3}{c}{ Ortalama Dağılım } \\
\cline { 3 - 5 } & & Faktör 1 & Faktör 2 & Genel \\
\hline Erkek & 165 & 136,81 & 133,14 & 134,19 \\
Kadın & 114 & 144,62 & 149,93 & 148,41 \\
\hline Mann Whitney U & & 8878,0 & 8272,5 & 8446,0 \\
Z & &,- 808 & $-1,712$ & $-1,450$ \\
p & &, 419 &, 087 &, 147 \\
\hline
\end{tabular}

${ }^{*} \mathrm{p}<=.05$

Tablo 8' de öğrencilerin bilgisayar programlamaya ilişkin öz yeterlik algıllarının cinsiyetlerine göre istatistiksel olarak anlamlı bir farklılık gösterip göstermediğini belirlemek amacıyla gerçekleştirilen Mann-Whitney U testi sonuçları görülmektedir. Sonuçlar öğrencilerin programlamaya ilişkin öz yeterlik algılarının cinsiyet $(\mathrm{U}=8446, \mathrm{p}=.147)$ değisskenine göre istatistiksel olarak anlamlı bir farklıllk göstermediği yönündedir. Bu sonuç Robinson'un (1995) programlama becerileri üzerine yaptığı bir araştırmasının sonuçları ile benzerlik göstermektedir. Bunun aksine Özyurt ve Özyurt, (2015) erkek öğrencilerin kız öğrencilere göre programlamaya karşı daha yüksek tutuma sahip oldukları (s. 12) sonucunu bulmuştur.

ii. Ö̈̆rencilerin programlamaya yönelik öz yeterlik alg1ları sınıf düzeylerine göre anlamlı bir farkll11k göstermekte midir?

Öğrencilerin programlamaya ilişkin öz yeterlik algılarının sınıf düzeylerine göre istatistiksel olarak anlamlı bir farklılık gösterip göstermediğini belirlemek amacıyla bağımsız gruplar için yapılan "Kruskal Wallis" sonuçları Tablo 9'de verilmiştir.

Tablo 9. Öğrencilerin Sınıf Düzeylerine Göre Programlamaya Yönelik Algılarına İlişkin Kruskal Wallis Testi Sonuçları

\begin{tabular}{|c|c|c|c|c|c|}
\hline & \multirow{2}{*}{ Sinif } & \multirow{2}{*}{$\mathbf{N}$} & \multicolumn{3}{|c|}{ Ortalama Dağılım } \\
\hline & & & Faktör 1 & Faktör 2 & Genel \\
\hline \multirow{7}{*}{ 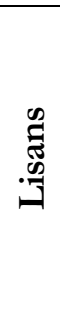 } & 1 & 32 & 67,39 & 79,80 & 76,19 \\
\hline & 2 & 31 & 103,63 & 80,34 & 88,27 \\
\hline & 3 & 43 & 76,85 & 70,79 & 70,76 \\
\hline & 4 & 59 & 85,11 & 95,03 & 92,85 \\
\hline & Kr. Wallis Chi-S $\left(\chi^{2}\right)$ & & 10,608 & 6,860 & 6,450 \\
\hline & $\mathrm{Z}$ & & 3 & 3 & 3 \\
\hline & $\mathrm{p}$ & & ,014 & ,076 & ,092 \\
\hline \multirow{6}{*}{ 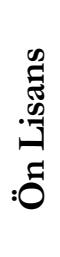 } & 1 & 38 & 67,86 & 71,66 & 71,28 \\
\hline & 2 & 72 & 53,53 & 50,82 & 51,49 \\
\hline & $2+$ & 4 & 30,63 & 43,25 & 34,88 \\
\hline & Kr. Wallis Chi-S $\left(\chi^{2}\right)$ & & 7,511 & 10,677 & 10,870 \\
\hline & Z & & 2 & 2 & 2 \\
\hline & $\mathrm{p}$ & & ,023 & ,005 & ,004 \\
\hline
\end{tabular}

BT öğretmen adaylarının programlamaya ilişkin öz yeterlik algıları sınıf düzeylerine göre; "basit programlama görevleri”" (U=10.608, $\mathrm{p}=.014)$ alt boyutunda anlamlı bir farklılık gösterirken, 
Yağc1, M. (2016). Bilişim teknolojileri (BT) öğretmen adaylarının ve bilgisayar programcıllğı (BP) öğrencilerinin programlamaya karşı tutumlarının programlama öz yeterlik algilarına etkisi. International Journal of Human Sciences, 13(1), 1418-1432. doi:10.14687/ijhs.v13i1.3502

"karmaş1k programlama görevleri” alt boyutunda anlamlı bir farkl1lı göstermemiştir. Bu sonuç BT öğretmen adaylarının programlamaya yönelik aldıkları ders sayısı arttıkça basit programlama görevlerini yerine getirme becerilerinin de arttı̆̆1 şeklinde yorumlanabilir. Ancak öğrencilerin aldıkları programlama ile ilgili dersler genel öz yeterlik alg1larını anlamlı bir şekilde değiştirmemiştir. BP öğrencilerinin programlamaya ilişkin öz yeterlik algıları ise sınıf düzeylerine göre her iki alt boyut için istatistiksel olarak anlamlı bir farklllık göstermiştir. Buradan BP öğrencilerine okutulan programlama derslerinin öğrencilerin öz yeterlik algılarına olumlu katkı sağladığı sonucunu çıkarabiliriz.

iii. Öğrencilerin programlamaya ilişkin öz yeterlik alg1ları mezun oldukları lise türüne göre anlamlı bir farkllilk göstermekte midir?

Öğrencilerin programlamaya ilişkin öz yeterlik algılarının mezun olunan lise türüne göre istatistiksel olarak anlamlı bir farklılık gösterip göstermediğini ölçmek amacıyla bağımsız gruplar için yapılan Kurskal Wallis testi sonuçları mezun olunan lise türünün programlamaya ilişkin öz yeterlik alg1sı $(\mathrm{U}=2.29, \mathrm{p}=.318)$ üzerinde anlamlı bir farklılık oluşturmadığ1 yönündedir.

iv. Öğrencilerin programlamaya ilişkin öz yeterlik alg1ları öğrenim düzeyine (lisans - ön lisans) göre anlamlı bir farklllık göstermekte midir?

Öğrencilerin öğrenim düzeylerine göre programlamaya ilişkin öz yeterlik algılarında anlamlı bir farklılık olup olmadığını ölçmek için yapılan Mann Whitney U testi sonuçları Tablo 10'da verilmiştir.

Tablo 10. Öğrenim Düzeyine Göre Bilgisayar Programlamaya Yönelik Öz Yeterlik Algılarına İlişkin Mann Whitney U Testi Sonuçları

\begin{tabular}{lcccc}
\hline \multirow{2}{*}{ Cinsiyet } & \multirow{2}{*}{$\mathbf{N}$} & \multicolumn{3}{c}{ Ortalama Dağ1lım } \\
\cline { 3 - 5 } & & Faktör 1 & Faktör 2 & Genel \\
\hline Ön Lisans & 114 & 109,39 & 98,96 & 98,24 \\
Lisans & 165 & 161,15 & 168,35 & 168,85 \\
\hline Mann Whitney U & & 5915,000 & 4727,000 & 4644,000 \\
Z & & $-5,349$ & $-7,072$ & $-7,200$ \\
p & &, 000 &, 000 &, 000 \\
\hline
\end{tabular}

${ }^{*} \mathrm{p}<=.01$

Tablo 10'dan Öğrencilerin öğrenim düzeyleri ile programlamaya ilişkin öz yeterlik algıları $(\mathrm{U}=4644, \mathrm{p}<.01)$ arasında <.01 anlamlılık düzeyinde istatistiksel olarak anlamlı bir farklılık olduğu görülmektedir. Bu farklılık BT öğretmen adaylarının lehinedir. Bu sonuc lisans düzeyinde öğrenim gören BT öğretmen adaylarının ön lisans düzeyinde öğrenim gören BP öğrencilerine göre çok daha yüksek düzeyde programlamaya ilişkin öz yeterlik algısına sahip olduklarını göstermektedir. Alanyazında bu araştırma sonucunu doğrular niteliktedir. Altun ve Mazman, (2012) Mühendislik bölümü öğrencilerinin BÖTE bölümü öğrencilerinden, BÖTE bölümü öğrencilerinin ise diğer bölümlerden anlamlı derecede yüksek öz yeterlik algisına sahip oldukları (s. 9) sonucuna ulaşmışlardır.

\section{e. BT öğretmen adaylarının ve BP öğrencilerinin bilgisayar programlamaya yönelik tutumları ile programlamaya ilişkin öz yeterlik algıları arasında anlamlı bir ilişki var mıdır?}

Elde edilen veriler normal dağılım göstermediğinden ilgili iki değişken arasındaki ilişki derecesini ölçmek için "Sperman sıra korelasyonu" analizi gerçekleştirilmiştir. Sperman sıra korelasyonu -1 ile +1 arasında değer almaktadır. Korelasyon katsayısının +1'e yakın olması değişkenler arasında pozitif yönlü, -1'e yakın olması ise negatif yönlü mükemmel bir ilişki olduğunu gösterir. Katsayının 0 olması ise değişkenler arasında doğrusal bir ilişkinin olmadığını gösterir (Kalayc1, 2009, s. 115). Tablo 11'de korelasyon katsayıları ile ilişki düzeyleri görülmektedir. 
Yağc1, M. (2016). Bilişim teknolojileri (BT) öğretmen adaylarının ve bilgisayar programcıllğı (BP) öğrencilerinin programlamaya karşı tutumlarının programlama öz yeterlik algilarına etkisi. International Journal of Human Sciences, 13(1), 1418-1432. doi:10.14687/ijhs.v13i1.3502

Tablo 11. Korelasyon katsayıları ve ilişki düzeyleri (Büyüköztürk 2009)

\begin{tabular}{ll}
\hline Mutlak Değer Aralığı (r) & İlişki Düzeyi \\
\hline $0.00-0.30$ & Düşük \\
$0.31-0.70$ & Orta \\
$0.71-1.00$ & Yüksek \\
\hline
\end{tabular}

Tablo 12'de öğrencilerin bilgisayar programlamaya yönelik tutumları ile programlamaya ilişkin öz yeterlik algıları arasındaki ilişkiye dair analiz sonuçları özetlenmiştir.

Tablo 12. Öğretmen Adaylarının Programlamaya İlişkin Öz Yeterlik Algıları İle Bilgisayar Programlamaya Yönelik Tutumları Arasındaki İlişki

\begin{tabular}{lcc}
\hline Bilgisayar Programlamaya Yönelik Tutum & & Genel Ortalama \\
\hline \multirow{2}{*}{ Programlamaya İlişkin Öz Yeterlik Algisı } & $\mathrm{r}$ &,- 032 \\
& $\mathrm{p}$ &, 599 \\
& $\mathrm{~N}$ & 279 \\
\hline
\end{tabular}

Tablo 12 incelendiğinde öğrencilerin bilgisayar programlamaya yönelik tutumları ile programlamaya ilişkin öz yeterlik algıları arasında anlamlı bir ilişki olmadığı görülmektedir ( $\mathrm{r}=$ .032). Buradan öğrencilerin bilgisayar programlamaya yönelik tutumlarının programlamaya ilişkin öz yeterlik algılarını etkilemediği sonucu çıkarılabilir. Mazman ve Altun, (2013) öğrencilerin programlamaya ilişkin öz yeterlik algısı ile akademik başarıları arasında yüksek düzeyde pozitif bir ilişki olduğunu (s. 4) ifade etmektedir. Benzer şekilde Ozyurt, (2015) da uzaktan eğitim öğrencilerinin programlamaya yönelik tutumları ile öz yeterlik düzeyleri arasında anlamlı bir ilişki bulmuştur. Literatürde bilgisayar programlama başarısını etkileyen çeşitli değişkenlere ilişkin araştırmalara da rastlamak mümkün. Örneğin bilişim teknolojileri öğretmeni adaylarının programlama sürecini etkileyen faktörleri inceleyen Özdinç ve Altun, (2014) program yazma ve program okuma görevlerinin farklı değişkenlerden etkilendiği (s. 8) sonucuna ulaşmıştır.

\section{Sonuç ve Öneriler}

Bu çalışma ile, BT öğretmen adaylarının ve BP öğrencilerinin bilgisayar programlamaya yönelik tutumlanı, programlamaya ilişkin öz yeterlik algıları ve bunlar arasındaki ilişki incelenmiştir. Tarama modelli çalışmanın örneklemini 165 BT öğretmen adayı ve 114 BP öğrencisi oluşturmaktadır. Araştırma sonuçları; hem BT öğretmen adaylarının ve hem de BP öğrencilerinin bilgisayar programlamaya yönelik tutumlarının orta düzeyde olduğunu göstermektedir. Programlamaya ilişsin öz yeterlik alg1sı da hem lisans ve hem de ön lisans öğrencileri için orta düzeyde olmasına rağmen lisans öğrencilerinin ortalama puanları daha yüksektir. Her iki öğrenci grubunun da aynı düzeyde tutuma ve öz yeterlik algisına sahip olmasının sebebi genellikle meslek lisesi mezunu olmalarından kaynaklanabilir. Meslek Yüksekokullarının BP bölümlerine meslek lisesi mezunları doğrudan geçiş yaparken Eğitim Fakültelerinin BÖTE bölümlerine gelen öğrenciler YGS-1'den ortalama 265 puan alarak yerleşmektedirler. Meslek liselerinden gelen öğrencilerin ayrıca ek puan aldıkları da düşünülürse çok az sayıda net ile BÖTE bölümlerine yerleşebilmektedirler. Programlama eğitimi alacak öğrencilerin üst düzey bilişsel düşünme ve üst düzey problem çözme becerilerine sahip olmaları gerektiği düşünüldüğünde bu öğrencilerin programlama eğitiminde neden başarılı olamadıkları daha iyi anlaşılmaktadır. Araştırmadaki her iki öğrenci grubunun da programlama öğrenmeye daha istekli olmaları gerekirken araştırma sonuçları tersi yönündedir.

Cinsiyete göre öğrencilerin bilgisayar programlamaya yönelik tutumlarında ve öz yeterlik algılarında anlamlı bir farklılık gözlenmemiştir. Buradan erkek ve kız öğrencilerin programlama eğilimlerinin benzer olduğu sonucunu çıkarabiliriz. Bir diğer araştırma bulgusu; BT öğretmen adaylarının devam ettikleri sınıfın programlamaya yönelik tutum ölçeğinin "programlamada başarıya karşı tutum" alt boyutunda 3. sınıfların lehine anlamlı bir farklılık gösterdiği, BP öğrencileri için ise 
Yağc1, M. (2016). Bilişim teknolojileri (BT) öğretmen adaylarının ve bilgisayar programcıllğı (BP) öğrencilerinin programlamaya karşı tutumlarının programlama öz yeterlik algılarına etkisi. International Journal of Human Sciences, 13(1), 1418-1432. doi:10.14687/ijhs.v13i1.3502

anlamlı bir farklılık göstermediğidir. BT öğretmen adaylarının sınıf düzeyleri programlamaya ilişkin Öz yeterlik algılarında anlamlı bir farklılık göstermezken BP öğrencilerinin öz yeterlik algılarında $<.01$ anlamlllık düzeyinde farklllık gözlenmiştir. Bu BP öğrencilerinin (2 yll süresince toplam 31 saat) BT öğretmen adaylarına (4 yıl süresince toplam 14 saat) göre çok daha fazla programlamaya ilişskin ders almalarından kaynaklanabilir.

Öğrencilerin mezun oldukları lise türüne göre programlamaya yönelik tutum ölçeğinin "programlamada başarıya karşı tutum" alt boyutunda Anadolu Meslek Lisesi mezunlarının lehinde anlamlı bir farklılık göstermiştir. Programlamaya ilişkin öz yeterlik algılarında ise iki boyut için de anlamlı bir farklılık göstermemiştir.

Araştırma sonuçlarından bir diğeri ise; lisans düzeyinde öğrenim gören BT öğretmen adaylarının ön lisans düzeyinde öğrenim gören BP öğrencilerine göre programlamaya ilişkin öz yeterlik algılarının daha yüksek olduğudur. Ayrıca BT öğretmen adayları ve BP öğrencilerinin bilgisayar programlamaya yönelik tutumları, ölçeğin "programlamada kendine güven ve güdüleme" alt boyutunda $\mathrm{p}<.001$ anlamlllı düzeyinde farklllık göstermektedir. Bu farkllık BT öğretmen adaylarının lehinedir.

Araştırma sonuçlarından sonuncusu; öğrencilerin bilgisayar programlamaya yönelik tutumları ile programlamaya ilişkin öz yeterlik algıları arasında anlamlı bir ilişki olmadığıdır.

Araştırma bulgularına göre aşağıdaki önerilerde bulunulabilir.

a. Programlama dilleri dersinin güçlügüunden yola çıkarak ders içerikleri öğrencilerin hedef kazanımlara ulaşma çabasını ve isteğini artıracak nitelikte tasarlanmalıdır.

b. Eğitim Fakültelerinin BÖTE ve Meslek Yüksekokullarının Bilgisayar Programcıllğı bölümlerine öğrenci alımında, programlama eğitiminin üst düzey problem çözme becerileri gerektirdiği gözönünde bulundurulmalıdır.

c. Fakültelerde ve Meslek Yüksekokullarında okutulan programlama derslerinin içeriği ve kazanımları öğrencilerin programlamaya yönelik algıları ve hazırbulunuşlukları gözönünde bulundurularak hazırlanmalıdır.

d. Programlamaya ilişkin yürütülen dersler yapısal programlama teknikleri ile bağlantılı alternatif programlama eğitimi yöntemleri ile yürütülmeli ve problem çözme becerileri kazandıracak nitelikte öğretimsel tasarıma sahip olmalıdır.

e. Farklı öğretimsel yöntemlerin kullanıldığı, öğrencilerin programlama başarılarını ölçen deneysel çalışmalar yapılmalıdır.

\section{KAYNAKÇA}

Altun, A., \& Mazman, S. G. (2012). Programlamaya İlişkin Öz Yeterlilik Alg1sı Ölçeğinin Türkçe Formumun Geçerlilik ve Güvenirlik Çalışması. Ë̆itimde ve Psikolojide Ölçme ve Değerlendirme Dergisi, 3(2), 297-308.

Askar, P., \& Davenport, D. (2009). An Investigation Of Factors Related To Self-Efficacy For Java Programming Among Engineering Students. The Turkish Online Journal of Educational Technology, 8(1).

Bakr, S. M. (2011). Attitudes of Egyptian Teachers towards Computers. Contemporary Educational Technology, 2(4), 308-318.

Başer, M. (2013a). Attitude , Gender and Achievement in Computer Programming. Middle-East Journal of Scientific Researc, 14(2), 248-255. doi:10.5829/idosi.mejsr.2013.14.2.2007

Başer, M. (2013b). Bïlgïsayar Programlamaya Karşı Tutum Ölçeğï Geliştïrme Çalışması *. The Journal of Academic Social Science Studies, 6(6), 199-215.

Brosnan, M. J. (1998). The Role Of Psychological Gender In The Computer-Related Attitudes And Attainments Of Primary School Children (Aged 6-11). Computers \& Education, 30(3), 203208. 
Yağc1, M. (2016). Bilişim teknolojileri (BT) öğretmen adaylarının ve bilgisayar programcıllğı (BP) öğrencilerinin programlamaya karşı tutumlarının programlama öz yeterlik algilarına etkisi. International Journal of Human Sciences, 13(1), 1418-1432. doi:10.14687/ijhs.v13i1.3502

Cetin, I., \& Ozden, M. Y. (2015). Development of computer programming attitude scale for university students. Computer Applications in Engineering Education, 23(5), 667-672. doi:10.1002/cae.21639

Forte, a., \& Guzdial, M. (2005). Motivation and Nonmajors in Computer Science: Identifying Discrete Audiences for Introductory Courses. IEEE Transactions on Education, 48(2), 248 253. doi:10.1109/TE.2004.842924

Haşlaman, T., \& Aşkar, P. (2007). Programlama Dersi İle İlgili Özdüzenleyici Öğrenme Stratejileri ve Başarı Arasındaki İlişkinin İncelenmesi. Hacettepe Üniversitesi Eğitim Fakültesi Dergisi, 32, $110-122$.

Kalaycı, Ş. (2009). SPSS Uygulamalı Çok Değişkenli İstatistik Teknikleri. ANKARA: Asil Yayın Dağıtım Ltd. Şti.

Korkmaz, Ö., \& Altun, H. (2013). Mühendislik ve BÖTE Öğrencilerinin Bilgisayar Programlama Öğrenmeye Dönük Tutumları. The Journal of Academic Social Science Studies, 6(2), 1169-1185.

Korkmaz, Ö., \& Demir, B. (2012). MEB Hizmetiçi Eğitimlerinin Öğretmenlerin Bilgi ve İletişim Teknolojilerine İlişkin Tutumlarına ve Bilgisayar Öz-Yeterliklerine Etkisi. Eğitim Teknolojisi Kuram ve Uygulama, 2(1), 1-18.

Lau, W. W. F., \& Yuen, A. H. K. (2009). Exploring the effects of gender and learning styles on computer programming performance: implications for programming pedagogy. British Journal of Educational Technology, 40(4), 696-712. doi:10.1111/j.1467-8535.2008.00847.x

Mazman, S. G., \& Altun, A. (2013). Programlama - I Dersinin BÖTE Bölümü Öğrencilerinin Programlamaya İlişkin Öz Yeterlik Algiları Üzerine Etkisi. Journal of Instructional Technologies \& Teacher Education, 2(3), 24-29.

Milic, J. (2009). Predictors Of Success In Solving Programming Tasks. The Teaching Mathmetics, 12(1), 25-31.

Ozyurt, O. (2015). An Analysis On Distance Education Computer Programming Students' Attitudes Regarding Programming And Their Self-Efficacy For Programming. Turkish Online Journal of Distance Education-TOJDE, 16(2), 111-121.

Özdinç, F., \& Altun, A. (2014). Bilişim Teknolojileri Öğretmeni Adaylarının Programlama Sürecini Etkileyen Faktörler. İlkögretim Online, 13(4), 1531-1541. doi:10.17051/io.2014.54872

Özyurt, Ö., \& Özyurt, H. (2015). Bilgisayar Programc1lŭ̆1 Öğrencilerinin Programlamaya Karş1 Tutum ve Programlama Öz Yeterliklerinin Belirlenmesine Yönelik Bir Çalışma. Eğitimde Kuram ve Uygulama, 11(1), 51-67.

Ramalingam, V. \& Wiedenbeck, S. (1998). Development and validation of scores on a computer programming self-efficacy scale and group analysis of novice programmer self-efficacy. Journal of Educational ComputingResearch, 19(4), 367-381.

Robinson, J. D. (1995). The Effects Of Two Approaches To Basic Programming On The Achievement and Field Dependent Students.

Uysal, M. P. (2014). Improving First Computer Programming Experiences : The Case of Adapting a Web-Supported and Well-Structured Problem- Solving Method to a Traditional Course. Contemporary Educational Technology, 5(3), 198-217.

Whitley, B. E. (1997). Gender differences in computer-related attitudes and behavior: A metaanalysis. Computers in Human Behavior, 13(1), 1-22. doi:10.1016/S0747-5632(96)00026-X

Wiebe, E. N., Williams, L., Yang, K., \& Miller, C. (2003). Computer Science Attitude Survey. Report No.: NCSU CSC TR-2003-1) Dept. of Computer Science, NC State University, Raleigh, NC. A, 23(4), 985-986. doi:10.1671/28

Yıldırım, S., \& Kaban, A. (2010). Öğretmen adaylarının bilgisayar destekli eğitime karşı tutumları. Uluslararasi Insan Bilimleri Dergisi, 7(2), 158-168. 
Yağc1, M. (2016). Bilişim teknolojileri (BT) öğretmen adaylarının ve bilgisayar programcıllğı (BP) öğrencilerinin programlamaya karşı tutumlarının programlama öz yeterlik algilarına etkisi. International Journal of Human Sciences, 13(1), 1418-1432. doi:10.14687/ijhs.v13i1.3502

\section{Extended English Abstract}

\section{Introduction}

Learning programming requires students to have high level of cognitive thinking skills (Lau \& Yuen, 2009). Students' success in programming course and acquisition of targets are subject to their problem solving skills and their attitude and self-sufficiency perceptions toward programming. In this regard, almost all of scientific researches in reported from Turkey indicate that students have low or medium level of attitude toward program development (Askar \& Davenport, 2009; Başer, 2013). Moreover, it was also reported in the relevant literature that students find programming education difficult.

Determination of attitudes of students toward programming and their perception regarding selfsufficiency would contribute into comprehension of student differences and ensuring transformation from teacher-centered education to student-centered education.

Many researches examining students' attitude toward programing and relationship between various demographic characteristics have been found in the literature. However, how students learn programming, students' attitudes and perceptions toward programing and the relationship between program and success are little-known issues. Determining students' attitudes and perceptions towards the programming can contribute to the understanding the differences in students and providing the transition from teacher-centered instruction to student-centered instruction. Additionally, examining the factors affecting the programming performance of the students in the literature is encouraged (Cetin \& Ozden, 2015; Mazman \& Altun, 2013; Korkmaz \& Altun, 2013; Başer, 2013). Advanced technological tools are commonly used in almost all academic fields. Hence, as Lau and Yuen (2009) indicated, programming learning skills play a fundamental role at the development of information literacy in educational technology. Conducting studies toward determining and developing programming skills of individuals who engage in education activities is also important. In this direction, the purpose of this study is to determine pre-service information technologies teachers' and computer programming students' attitudes and self-efficacy beliefs toward computer programming and examine the relationship between them.

\section{Method}

Within the scope of the study, 279 respondents were reached through form and survey in the internet environment. "Self-sufficiency scale for programming" and "attitude scale for computer programming" were utilized for data collection. During analysis of the collected data, frequency (f), percentage (\%), mean $(\mathrm{X})$ and standard deviation $(\mathrm{Sd})$ values in descriptive statistics; Kruskall Wallis and Mann-Whitney $U$ tests in exploratory statistic techniques were utilized. In order to determine correlation between attitudes of participants toward computer programming and their selfsufficiency perception toward programming, Sperman rank correlation tests were utilized.

\section{Findings and Results}

Sampling group of this study structured with screening model is consisted of 165 IT preservice teacher and 114 CP students. Research results suggest that attitudes of both IT preservice teachers and CP students toward computer programming are at medium level. Although their selfsufficiency perception toward programming is at medium level for both bachelor and associate degree students; mean scores of bachelor degree students are higher. The reason for both student groups has the same level of attitude and self-sufficiency perception could usually be that they are all graduated from vocational high school. While vocational high school graduates are directly transferred to the CP Departments of Vocational Colleges; students can be accepted by Computer Education and Instructional Technology (CEIT) Departments of Educational Science Departments based on such their YGS-1 score as low as 265. When it is considered that students who will 
Yağc1, M. (2016). Bilişim teknolojileri (BT) öğretmen adaylarının ve bilgisayar programcıllğı (BP) öğrencilerinin programlamaya karşı tutumlarının programlama öz yeterlik algılarına etkisi. International Journal of Human Sciences, 13(1), 1418-1432. doi:10.14687/ijhs.v13i1.3502

receive programming education need to have high level of cognitive thinking and problem solving skills (Lau \& Yuen, 2009), it can be better understood why these students experience failure in programming education. In another study, it was reported that IT preservice teachers at bachelor degree have significantly higher level of self-sufficiency perception toward programming with respect to $\mathrm{CP}$ students in associate degree. Moreover, attitudes of IT prospect teachers and $\mathrm{CP}$ students toward computer programming exhibit difference in the "self-confidence and motivation in programming" sub-dimension of scale on $\mathrm{p}<.001$ significance level in favor of IT preservice teachers.

Another research reports that there is no significant correlation between attitudes of students toward computer programming and their self-sufficiency perception toward programming.

According to research findings, following suggestions can be drawn:

a. Based on the difficulty of programming languages course, course content must be designed in a way supporting and enhancing efforts and will of students to gain target acquisitions.

b. In student recruitment process for CEIT Departments of Educational Science Faculties and Computer Programming Departments of Vocational Colleges, it must be taken into consideration that programming education requires high level of problem solving skills.

c. Acquisitions and contents of programming courses given in faculties and vocational colleges must be prepared according to students' perception and readiness toward programming.

d. Courses taught in programming field must be conducted relevant with structural programming techniques by means of alternative programming education methods; and they must have teaching design to ensure that students gain problem solving skills.

e. Experimental studies which measures students' success in programming, must be implemented in which different teaching methods are used. 